University of Wollongong

Research Online

Faculty of Engineering and Information

Faculty of Engineering and Information

Sciences - Papers: Part A

Sciences

$1-1-2015$

\title{
Experimental study on the properties of corroded steel fibres
}

\author{
Gang Chen \\ University of Wollongong \\ Muhammad N. S Hadi \\ University of Wollongong, mhadi@uow.edu.au \\ Danying Gao \\ Zhengzhou University \\ Liangping Zhao \\ Zhengzhou University
}

Follow this and additional works at: https://ro.uow.edu.au/eispapers

Part of the Engineering Commons, and the Science and Technology Studies Commons

Research Online is the open access institutional repository for the University of Wollongong. For further information contact the UOW Library: research-pubs@uow.edu.au 


\title{
Experimental study on the properties of corroded steel fibres
}

\begin{abstract}
In this study, low carbon steel fibres were corroded to various corrosion degrees by cycling in $3.5 \% \mathrm{NaCl}$ solution and $60^{\circ} \mathrm{C}$ oven, and by applying a designed current density of $20 \mathrm{~mA} / \mathrm{cm} 2$. Then the corrosion characters and corrosion degree on tensile strength of the two types of corroded steel fibres were investigated. It was found that the cycles induce pitting and the current induces relatively uniform corrosion. The results of tensile test show that the actual tensile strength of steel fibres was reduced in the case of pitting, while it was marginally affected by uniform corrosion. As the corrosion degree increased, both of the nominal tensile strength and elongation of the two types of corroded steel fibres decreased. In addition to weight loss, local section loss at the pits is the main reason for further degradation of the mechanical properties of steel fibres and gives a brittle failure.

Disciplines

Engineering | Science and Technology Studies

\section{Publication Details}

Chen, G., Hadi, M. N. S., Gao, D. \& Zhao, L. (2015). Experimental study on the properties of corroded steel fibres. Construction and Building Materials, 79 165-172.
\end{abstract}




\title{
Experimental study on the properties of corroded steel fibres
}

\author{
Gang Chen ${ }^{\mathrm{a}, \mathrm{b}}$, Muhammad N.S. Hadi ${ }^{\mathrm{b}, *}$, Danying Gao ${ }^{\mathrm{a}}$, Liangping Zhao ${ }^{\mathrm{a}}$
}

${ }^{\mathrm{a}}$ Research Centre of New Style Building Material and Structure, Zhengzhou University, Zhengzhou, Henan 450002, China

${ }^{b}$ Faculty of Engineering and Information Sciences, University of Wollongong, NSW 2522, Australia

\section{Highlights}

Steel fibres were corroded using two methods: drying-wetting cycles and current.

The two corrosion methods show pitting and uniform corrosion respectively.

Pitting corrosion leads to higher decrease in tensile strength compared to uniform corrosion.

Pitting induces a significant reduction in elongation giving a brittle failure.

\begin{abstract}
In this study, low carbon steel fibres were corroded to various corrosion degrees by cycling in $3.5 \%$

$\mathrm{NaCl}$ solution and $60^{\circ} \mathrm{C}$ oven, and by applying a designed current density of $20 \mathrm{~mA} / \mathrm{cm}^{2}$. Then the corrosion characters and corrosion degree on tensile strength of the two types of corroded steel fibres were investigated. It was found that the cycles induce pitting and the current induces relatively uniform corrosion. The results of tensile test show that the actual tensile strength of steel fibres was reduced in the case of pitting, while it was marginally affected by uniform corrosion. As the corrosion degree increased, both of the nominal tensile strength and elongation of the two types of corroded steel fibres decreased. In addition to weight loss, local section loss at the pits is

\footnotetext{
* Corresponding author. Tel.: +61 24221 4762; fax: +61 242213238.

E-mail address: mhadi@uow.edu.au (M.N.S Hadi).
} 
the main reason for further degradation of the mechanical properties of steel fibres and gives a brittle failure.

Keywords: steel fibre; corrosion; mechanical properties

\section{Introduction}

Steel fibres in concrete are widely used for roads, bridges, tunnels, marine structures and some other main building structures [1]. However, steel fibres just like steel bars, could be corroded by chloride ions in certain environments.

Cases of performance degradation and resistance attenuation of structures, mainly due to the effect of severe corrosion of steel bars, are common occurrence and were studied by many researchers [2-6]. The performance of a steel bar may not be affected significantly by a thin layer of corrosion. However, the effect of a thin layer of corrosion on the performance of a steel fibre whose equivalent diameter is much smaller than steel bar diameter, is particularly serious [7]. Jin et al. [8] analysed the relationship between the diameter of a steel bar and the thickness of corrosion layer. They concluded that the steel bars with various diameters usually have the same corrosion thicknesses in the same corrosive condition. In this case, the steel bar with smaller diameter should have a higher corrosion degree. Similarly, the steel fibre can be considered as a very small steel bar in diameter compared to normal steel bar. Once they are exposed to a corrosive environment, the corrosion rate of steel fibre will be much higher than that of a steel bar.

In normal conditions, the steel fibres are protected by concrete and not easy to be corroded. The physical protection is provided by dense and relatively impermeable structure of concrete, while 
the chemical protection is provided by high alkalinity $(\mathrm{pH}>13.5)$ of the pore solution in concrete [9]. At this high alkalinity, steel is passivated in the presence of oxygen probably as a result of the formation of an extremely thin film $[10,11]$. Unless the chloride ions penetrate into the steel fibre concrete and exceed the critical threshold value of corrosion, this film can not be destroyed and believed to protect the surface of steel fibre from corrosion. Therefore, even in a corrosive environment, such as deicing salt and sea water containing chloride ions with relatively high concentration, only steel fibres embedded in very shallow concrete cover which can easily be in contact with surface diffused chloride ions are susceptible to corrosion [12, 13].

However, when the steel fibres are exposed to concrete cracks over a certain width, thus giving access of chloride ions, water and oxygen, they will be corroded easily. Granju et al. [14] exposed the cracked steel fibre reinforced concrete (SFRC) to a marine-like environment for one year and then evaluated the corrosion of steel fibres located in cracked sections. Their results indicated that there is absence of corrosion in the parts of the cracks thinner than about $0.1 \mathrm{~mm}$, while a little corrosion was observed in the wider parts of the cracks with $0.5 \mathrm{~mm}$ mouth openings and extensive corrosion appears in the fibres crossing the crack within a $2-3 \mathrm{~mm}$ rim from the external faces of the samples. Moreover, no concrete busting or spalling was observed due to corrosion. Testing the specimens showed an increased strength gain from the rough surface of steel fibres with little corrosion. But when the corrosion reaches a severe degree, the degraded strength affected by corrosion could not resist the tensile stress. Meanwhile, the corroded steel fibres acting as a bridge in cracks no longer have better performance on anti-cracking, enhancement, toughening for SFRC [7, 15].

Kosa et al. [7] studied the effects of the corrosion degree on the mechanical performance of SFRC 
using two series of specimens. One was to expose cracked, carbonated and high permeability specimens with clean steel fibres into cycles of intermittent drying and wetting for varying period and solution temperatures, while the other one was for specimens with steel fibres pre-corroded by similar cycles. The results obtained from the loading tests of the two series showed a similar trend: their overall mechanical properties presented a deteriorating trend caused by increasing reduction of minimum fibre diameter; the severely corroded steel fibres in the specimen underwent breakage in tension and bending, and gave rise to a noticeable reduction in toughness as well as peak strength of tension and bending for specimens. Similarly, Regina [15] conducted mechanical tests on concrete specimens with the steel fibres pre-corroded to $0 \%, 12.5 \%$ and $50 \%$ reduction in the minimum fibre diameter using drying-wetting cycles. The observation indicated that the failure type of steel fibres was changed from typical pullout to fracture with increasing corrosion degree. The experimental results demonstrated that fibre corrosion less than $12.5 \%$ had no effect on the shear capacity, while $50 \%$ corrosion led to a decreased shear strength of the beam by $24 \%$. Furthermore, the toughness and ductility of SFRC were affected by corrosion to a much higher extent than the shear strength.

Obviously, the properties of steel fibres affected by corrosion are directly related to the performances of SFRC. However, the corrosion characteristics and the effect of corrosion degree on the mechanical properties of steel fibres are barely studied by researchers and are investigated in this paper.

\section{Experimental programme}

\subsection{Test samples and corrosion methodology}

The experimental programme of this study was carried out at the Engineering Laboratories of the 
University of Wollongong. A total of 70 low carbon hooked steel fibres glued in bundles with the same length of $60 \mathrm{~mm}$ and $0.75 \mathrm{~mm}$ diameter were separated and used for this experiment. In order to achieve the desired corrosion degrees within a short time, the accelerated corrosion technique was adopted for the corrosion of steel fibres.

The first group of 35 steel fibres, named Group D, corroded using drying-wetting cyclic method at the same time. Each cycle consisted of 1 hour of saturation in a $3.5 \mathrm{wt} \% \mathrm{NaCl}$ solution (mixing industrial sodium chloride with tap water of $\mathrm{pH}$ 7.4-7.7 [16] , concentration similar to seawater with $3.2-3.6 \mathrm{wt} \%$ [7]) at ambient temperature $\left(20-27^{\circ} \mathrm{C}\right)$, followed by 11 hours of drying at $60^{\circ} \mathrm{C}$ in an oven. The solution was renewed every four cycles. The desired corrosion period was set for 5 to 60 days.

For comparison, the second group of 30 steel fibres, named Group G, was corroded using galvanostatic method. Fig. 1 shows a schematic representation of the corrosion set-up of this method, which is described as follows: One end of the prepared steel fibre was hung on the inside wall of a plastic tank containing $5 \mathrm{wt} \% \mathrm{NaCl}$ solution for improving the conductivity. The top and exposed end with $5 \mathrm{~mm}$ in length of every sample was connected to the anode of a HP Harrison 622B power supply in parallel. Its cathode was connected to a hollow stainless steel bar immersed in $\mathrm{NaCl}$ solution. The current density $i$ of $20 \mathrm{~mA} / \mathrm{cm}^{2}$ was adopted in this accelerated corrosion. The desired corrosion degree $\eta, 2 \%$ to $80 \%$ in weight loss rate, was achieved by applying a constant current $I$ (A) for the period of corrosion time $t$ (s) assessed from the Faraday law:

$$
\begin{gathered}
t=\frac{\eta W z F}{M I} \\
I=A \times i \times 10^{-3}
\end{gathered}
$$


Where $W$ is the weight of original steel fibre (g), $Z$ is ionic valency, $Z=2.5$ (mean value for $\mathrm{Fe}^{2+}$ and $\mathrm{Fe}^{3+}$ of corrosion products [2]), $F$ is Faraday's constant, $F=96,500 \mathrm{C} / \mathrm{mol}, M$ is the atomic weight of ferric ion, $M=56 \mathrm{~g} / \mathrm{mol}, A$ is surface area $\left(\mathrm{cm}^{2}\right)$.

To ensure the accuracy of corrosion results, in the process of corrosion, the loading current $I$ was checked and corrected to a right value regularly based on the current density $i$ and residual surface area $A$ :

$$
A=2 \sqrt{\frac{\pi l}{\rho} \cdot W(1-\eta)}
$$

Where $\rho$ is the density of steel, $\rho=7.9 \mathrm{~g} / \mathrm{cm}^{3}$.

The last group of five clean steel fibres, named Group C, served as control. After corrosion, the three groups of steel fibres, Group D, Group G and Group C, were prepared for tensile test to investigate their mechanical properties.

\subsection{Tensile test and measurement of corrosion}

The Instron 4302 with a load capacity of $10 \mathrm{kN}$ was used for the tensile test. To make it possible to obtain a stable grip, both hooked ends (5 $\mathrm{mm}$ in length at either end) of every steel fibre of the three groups were cut off. Then the middle straight fibre with $50 \mathrm{~mm}$ in total length was preserved for testing. In this test, each sample was wrapped by paper mesh to protect it from premature breakage caused by grip teeth and to sustain a uniform load. The gap between the two grips was adjusted to $1.5 \mathrm{~mm}$ and the ramp rate was set at $0.3 \mathrm{~mm} / \mathrm{min}$. The real-time load and extension were collected by data taker at a rate of two readings per second.

In order to measure the corrosion degree of the corroded steel fibres after tensile test, the two pieces of each fractured fibre were cleaned to remove the corrosion using fine sand paper and 
brush. Then, the weight was measured by a scale and their corrosion degree was assessed using weight loss rate.

\section{Results and Discussion}

\subsection{Visual inspection}

As can be seen in Fig. 2, the controls of Group C had a smooth surface, while the surface appearance of the corroded samples of Group D presents a correlation with the period of drying-wetting cycles. A rough layer of hard corrosion products with a reddish brown colour appears on the sample surface exposed to cycles for 5 days and 10 days. When exposed for 20 to 60 days, the colour of the surface gradually deepen to dark reddish brown which is the result of increased mass of attached corrosion products. Meanwhile, many raised spots were distributed on the surface. In terms of the samples experienced for 50 days and 60 days, the corrosion layer with flaky and blocky corrosion became thicker, and easy to drop off. After surface cleaning, all of the corroded samples displayed many pits on the surface, and with higher corrosion degree, more and deeper pits appearance were observed by optical microscope, as shown in Fig. 3. This pitting corrosion is characterized for the situation where passivation film is destroyed. The destroyed areas exposed to $\mathrm{NaCl}$ was consumed by an anodic electrochemical reaction [17]:

$$
\mathrm{Fe} \rightarrow \mathrm{Fe}^{2+}+2 \mathrm{e}^{-}
$$

While the cathodic electrochemical reaction performed on its protected area and hardly consumed the steel [17]:

$$
\mathrm{H}_{2} \mathrm{O}+\frac{1}{2} \mathrm{O}_{2}+2 \mathrm{e}^{-} \rightarrow 2 \mathrm{OH}^{-}
$$


The anodic reaction and cathodic reaction that coexist in the same fibre will lead to the fact that the difference of the cross section between the destroyed area and the protected area appear. Therefore, the corrosion of samples experienced for drying-wetting cycles is not uniform.

Fig. 4 shows the surface appearance for corroded steel fibres of Group D. Unlike Group D samples, they only exhibit a thin layer of corrosion products with reddish brown or dark reddish brown attached to their surface at all achieved corrosion degrees, noticed by naked eyes. After surface corrosion cleaning, a relatively uniform cross section appeared. This uniform corrosion was obtained from the separated electrochemical reactions. The anodic reaction consuming the steel performed on the whole fibres, while the cathodic reaction only occurred on the stainless steel bar. Thus, the distribution of corrosion on the surface steel served as anode is uniform [18].

\subsection{Effect of corrosion degree on the mechanical properties of steel fibres}

The tensile strength of steel fibres was evaluated by actual tensile and nominal tensile strength. The actual tensile strength was determined by using the minimum diameter measured with a vernier caliper, while the nominal tensile strength was calculated by using the nominal diameter of $0.75 \mathrm{~mm}$.

The actual tensile strength for the tested steel fibres with no corrosion and corroded steel fibres of the two groups with varying corrosion degree are summarized in Tables 1 and 2. The liner regression analyses of test data suggested the actual strength ratio $f_{\mathrm{a}} / f_{0}$ can be determined by equations (6) plotted in Fig. 5:

$$
f_{\mathrm{a}} / f_{0}=\left\{\begin{array}{lll}
1.028-0.016 \cdot \eta & \mathrm{R}^{2}=0.643 & \text { for Group } \mathrm{D} \\
1.076+0.002 \cdot \eta & \mathrm{R}^{2}=0.189 & \text { for Group } \mathrm{G}
\end{array}\right.
$$


The results indicate that the ultimate load of the steel fibres decreased as the corrosion degree increased. Meanwhile, the actual tensile strength of Group D samples was reduced by corrosion significantly. However, the corrosion degree did not reduce the actual tensile strength of Group G samples due to a compatible decrease of cross section with ultimate load.

The actual tensile strength of Group D samples with 32.5\% weight loss rate decrease to $648 \mathrm{MPa}$ which only have a strength ratio $f_{\mathrm{a}} / f_{0}$ of 0.52 . But the Group $\mathrm{G}$ samples corroded to $87.5 \%$ still have a high actual tensile strength of $1281 \mathrm{MP}$ with a strength ratio $f_{\mathrm{a}} / f_{0}$ of 1.02 . Although these steel fibres experienced corrosion, the actual strength of both groups of corroded samples is still more than $310 \mathrm{MPa}$ as specified by ASTM A820 [19].

Tables 1 and 2 also summarize the nominal tensile strength of the corroded steel fibres of the two groups with varying corrosion degree. The liner regression of these data presents in following:

$$
f_{\mathrm{n}} / f_{0}=\left\{\begin{array}{lll}
0.940-0.021 \cdot \eta & \mathrm{R}^{2}=0.816 & \text { for Group D } \\
1.062-0.011 \cdot \eta & \mathrm{R}^{2}=0.981 & \text { for Group G }
\end{array}\right.
$$

Above results indicate that, with an increase of corrosion degree, the nominal tensile strength of Group D samples decrease more rapidly than does Group G samples, as shown in Fig. 6. For example, when a sample of group D was corroded to $28.3 \%$, its nominal tensile strength drops to $201 \mathrm{MPa}$, with a strength ratio $f_{\mathrm{n}} / f_{0}$ of 0.16 , which is lower than 310 MPa specified by ASTM A820 [19]. However, the nominal tensile strength of group G samples does not fall to the specified value of ASTM A820 [19] until the samples were corroded up to $75.1 \%$.

The experimental results indicate that even at high corrosion degree, there is marginal change in the actual tensile strength of steel fibres of Group G with a uniform corrosion. However, the steel 
fibres of Group D with pits were weaker in actual tensile strength. From the comparison of corrosion characteristics and tensile strength, it is clear that, the pitting corrosion resulting in the local section loss has more considerable effect on tensile strength than does uniform corrosion. Besides the expected reduction of strength caused by a decreased uniform section loss, an extra reduction of strength was caused by localized stress concentration at these pits. As a result, the local section loss of the pits gives rise to a premature failure and significant decrease of strength.

\subsection{Effect of corrosion degree on fracture mode of steel fibres}

Group C control samples showed a typical load-elongation curve with intact elastic phase and plastic phase, as shown in Fig. 7. With corrosion raising up to $12.68 \%$, the plastic phase of Group D samples was shorter and displayed sensitivity to corrosion. Eventually, these samples exhibited a sudden failure with no plastic phase, i.e., the curves of $19.7 \%$ weight loss rate and above. In contrast to Group D, although the curves of Group G got short with the increase of corrosion, the shape of these curves does not change substantially, just like the Group C curve, and still have intact elastic phase and obvious plastic phase except one sample with $87.5 \%$ weight loss rate, as shown in Fig. 8.

The results indicate that a steel fibre with uniform corrosion can undergo plastic deformation over a significant length. However, in the case of pitting, the local section loss will reduce the elongation significantly. When an axial tensile load is applied on these pits of steel fibres, the strain would be concentrated at these pits and the overall strain of steel fibre will decrease resulting in a brittle failure. Commonly, the steel fibres with no corrosion have sufficient tensile strength to be pulled out from a concrete matrix giving a ductile behaviour of a structure. A 
reduced cross section will give a tensile failure of the steel fibres instead and a more brittle failure, reported by Nordström [20].

\section{Conclusions}

Based on the experimental results of this study, the following conclusions are drawn:

1. The steel fibres corroded to $0.47-32.49 \%$ in weight loss using drying-wetting cyclic method exhibiting pitting corrosion, while the steel fibres corroded to $1.81-87.48 \%$ using galvanostatic method show a relatively uniform corrosion.

2. Within the achieved corrosion degree, the ultimate load carried by corroded steel fibres decrease with increasing weight loss. A significant reduction in the actual tensile strength of the steel fibres with pitting corrosion was observed due to possible stress concentration at these pits. However, it is not reduced by corrosion for steel fibres with relatively uniform corrosion. All of the tested corroded steel fibres show a decrease in the nominal tensile strength with increasing weight loss.

3. Pitting on steel fibres could cause a severe degradation of elongation because of the strain concentrated at these pits and result in a brittle failure. Whereas, the elongation of steel fibres with relatively uniform corrosion decrease regularly along with the increase of corrosion degree.

In cracked concrete giving access of chloride ions, water and oxygen, the corrosion is limited to the exposed section of the steel fibres [21]. The steel fibres crossing the cracks are usually the weakest section where failure occurred easily. Pitting induced local section loss would appear on the steel fibres exposed to these corrosive materials, observed from this experimental results. It is known that, the pitting corrosion has significant negative effect on mechanical performance. When 
the steel fibre strength is reduced by corrosion to below the pull-out load for the majority of the steel fibres in concrete, the mechanism of steel fibre concrete will fail in a more brittle manner [22].

\section{References}

[1] Swamy R, Lankard D. Some practical applications of steel fibre reinforced concrete. ICE Proceedings1974. p. 235-56.

[2] Lu C, Jin W, Liu R. Reinforcement corrosion-induced cover cracking and its time prediction for reinforced concrete structures. Corrosion Science. 2011;53(4):1337-47.

[3] Cairns J, Plizzari GA, Du Y, Law DW, Franzoni C. Mechanical properties of corrosion-damaged reinforcement. ACI Materials Journal. 2005;102(4):256-64.

[4] Palsson R, Mirza MS. Mechanical response of corroded steel reinforcement of abandoned concrete bridge. ACI Structural Journal. 2002;99(2):157-62.

[5] Rodriguez J, Ortega LM, Casal J. Load carrying capacity of concrete structures with corroded reinforcement. Construction and Building Materials. 1997;11(4):239-48.

[6] Auyeung Y, Balaguru P, Chung L. Bond behavior of corroded reinforcement bars. ACI Materials Journal. 2000;97(2):214-20.

[7] Kosa K, Naaman AE. Corrosion of steel fiber reinforced concrete. ACI Materials Journal. 1990;87(1):27-37.

[8] Jin W, Zhao Y, Yan F. The mechanism of corroded expansion force of reinforced concrete members. Journal of Hydraulic Engineering. 2001(07):57-62. (in Chinese)

[9] Almusallam AA. Effect of degree of corrosion on the properties of reinforcing steel bars. Construction and Building Materials. 2001;15(8):361-8.

[10] Pourbaix M. Atlas of electrochemical equilibria in aqueous solutions. New York: Pergamon Press; 1966.

[11] Pourbaix M. Applications of electrochemistry in corrosion science and in practice. Corrosion Science. 1974;14(1):25-82.

[12] Balouch SU, Forth JP, Granju JL. Surface corrosion of steel fibre reinforced concrete. Cement and Concrete Research. 2010;40(3):410-4.

[13] Hoff G. Durability of fiber reinforced concrete in a severe marine environment. Concrete Durability-Katharine and Bryant Mather International Conference SP-100. Detroit: American Concrete Institute; 1987. p. 997-1041.

[14] Granju J-L, Balouch SU. Corrosion of steel fibre reinforced concrete from the cracks. Cement and Concrete Research. 2005;35(3):572-7.

[15] Waweru RN. The effect of fiber corrosion on shear capacity of steel fiber reinforced concrete beams and an initial investigation on alkali-silica reaction in steel fiber reinforced concrete [M.S.]. United States - Texas: The University of Texas at Arlington; 2011.

[16] Water Sydney. Quarterly Drinking Water Quality Report. 2013.

[17] Ma FY. Corrosive Effects of Chlorides on Metals. In: Bensalah N, editor. Pitting Corrosion: InTech; 2012. p. 139-78.

[18] Yuan YS, Zhang XS, Ji YS. A comparative study on structural behavior of deteriorated reinforced concrete beam under two different environments. China Civil Engineering Journal. 2006;39(03):42-6. (in Chinese) 
[19] ASTM A820/A820 M. Standard specification for steel fibers for fiber-reinforced concrete. West Conshohocken, UnitedStates: Am SocTest Mater; 2011.

[20] Nordström E. Steel fibre corrosion in cracks durability of sprayed concrete. SWEDEN: Lulea University of Technology; 2000.

[21] Aufmuth RE, Naus DJ, Williamson GR. Effect of aggressive environment on steel fibre reinforced concrete. Letter Report M-113. Chaimpaign, IL: Construction, Engineering Research Laboratory; 1974. [22] Hannant DJ, Edgington J. Durability of Steel Fibre Concrete. Fibre Reinforced Cement and Concrete (RILEM Symposium). London: Construction Press; 1975. p. 159-69. 
List of Tables

Table 1. Tensile strength for steel fibres corroded by drying-wetting cycles and controls

Table 2. Tensile strength for steel fibres corroded using galvanostatic method 
Fig. 1. Schematic representation of the set up for accelerated corrosion using galvanostatic method

Fig. 2. Steel fibres after exposing to drying-wetting cycles

Fig. 3. Pitting of steel fibres with varying degrees of corrosion

Fig. 4. Steel fibres corroded by galvanostatic method

Fig. 5. Actual tensile strength ratio for corroded steel fibres with varying degrees of corrosion

Fig. 6. Nominal tensile strength ratio for corroded steel fibres with varying degrees of corrosion

Fig. 7. Load-elongation curves for steel fibres corroded by drying-wetting cycles

Fig. 8. Load-elongation curves for steel fibres corroded using galvanostatic method 
Table 1. Tensile strength for steel fibres corroded by drying-wetting cycles and controls

\begin{tabular}{|c|c|c|c|c|c|}
\hline $\begin{array}{c}\text { Weight Corrosion } \\
\text { Rate } \\
\eta_{\mathrm{m}}(\%)\end{array}$ & $\begin{array}{l}\text { Ultimate Load } \\
\qquad P(\mathrm{~N})\end{array}$ & $\begin{array}{l}\text { Actual ultimate } \\
\text { Strength } \\
f_{\mathrm{a}}(\mathrm{MPa})\end{array}$ & $\begin{array}{c}\text { Nominal ultimate } \\
\text { Strength } \\
f_{\mathrm{n}}(\mathrm{MPa})\end{array}$ & $f_{\mathrm{a}} / f_{0}$ & $f_{\mathrm{n}} / f_{0}$ \\
\hline 0.00 & 555.28 & 1251.70 & 1251.70 & 1.00 & 1.00 \\
\hline 0.47 & 566.64 & 1391.72 & 1282.61 & 1.11 & 1.02 \\
\hline 0.47 & 556.91 & 1330.61 & 1260.59 & 1.06 & 1.01 \\
\hline 1.22 & 524.08 & 1252.16 & 1186.27 & 1.00 & 0.95 \\
\hline 1.35 & 540.08 & 1290.39 & 1222.49 & 1.03 & 0.98 \\
\hline 1.45 & 549.90 & 1313.85 & 1244.71 & 1.05 & 0.99 \\
\hline 1.55 & 510.59 & 1254.05 & 1155.74 & 1.00 & 0.92 \\
\hline 1.65 & 474.09 & 1197.44 & 1073.12 & 0.96 & 0.86 \\
\hline 1.67 & 498.13 & 1223.45 & 1127.53 & 0.98 & 0.90 \\
\hline 2.81 & 494.00 & 1283.64 & 1118.19 & 1.03 & 0.89 \\
\hline 4.67 & 521.22 & 1280.18 & 1179.81 & 1.02 & 0.94 \\
\hline 4.77 & 394.61 & 1025.38 & 893.22 & 0.82 & 0.71 \\
\hline 6.75 & 394.56 & 1055.19 & 893.11 & 0.84 & 0.71 \\
\hline 7.39 & 378.06 & 1011.05 & 855.75 & 0.81 & 0.68 \\
\hline 9.62 & 402.13 & 1107.27 & 910.22 & 0.88 & 0.73 \\
\hline 10.20 & 414.15 & 1210.55 & 937.45 & 0.97 & 0.75 \\
\hline 12.68 & 369.89 & 1018.52 & 837.27 & 0.81 & 0.67 \\
\hline 13.44 & 409.68 & 1356.96 & 927.31 & 1.08 & 0.74 \\
\hline 13.56 & 361.21 & 1055.81 & 817.62 & 0.84 & 0.65 \\
\hline 14.01 & 291.35 & 802.25 & 659.48 & 0.64 & 0.53 \\
\hline 14.27 & 380.63 & 1017.92 & 861.57 & 0.81 & 0.69 \\
\hline 14.29 & 312.91 & 1003.81 & 708.29 & 0.80 & 0.57 \\
\hline 14.79 & 207.81 & 607.43 & 470.39 & 0.49 & 0.38 \\
\hline 17.26 & 245.14 & 738.75 & 554.88 & 0.59 & 0.44 \\
\hline 19.71 & 300.23 & 1027.31 & 679.58 & 0.82 & 0.54 \\
\hline 21.43 & 259.65 & 860.04 & 587.73 & 0.69 & 0.47 \\
\hline 22.11 & 230.43 & 1128.01 & 521.59 & 0.90 & 0.42 \\
\hline 23.34 & 285.93 & 917.26 & 647.22 & 0.73 & 0.52 \\
\hline 24.94 & 397.13 & 1062.05 & 898.92 & 0.85 & 0.72 \\
\hline 25.28 & 213.55 & 836.88 & 483.38 & 0.67 & 0.39 \\
\hline 27.11 & 280.42 & 819.66 & 634.74 & 0.65 & 0.51 \\
\hline 27.22 & 173.19 & 728.96 & 392.02 & 0.58 & 0.31 \\
\hline 28.31 & 88.76 & 417.95 & 200.91 & 0.33 & 0.16 \\
\hline 29.93 & 199.52 & 705.64 & 451.61 & 0.56 & 0.36 \\
\hline 32.49 & 142.86 & 647.54 & 323.37 & 0.52 & 0.26 \\
\hline 33.38 & 146.24 & 573.08 & 331.01 & 0.46 & 0.26 \\
\hline
\end{tabular}

* The data of $0.00 \%$ corrosion are average of controls.

* $f_{\mathrm{a}} / f_{0}$ is a ratio of actual tensile strength of corroded steel fibre and average tensile strength of controls;

$f_{\mathrm{n}} / f_{0}$ is a ratio of nominal tensile strength of corroded steel fibre and average tensile strength of controls. 
Table 2. Tensile strength for steel fibres corroded using galvanostatic method

\begin{tabular}{|c|c|c|c|c|c|}
\hline $\begin{array}{c}\text { Weight } \\
\text { Corrosion Rate } \\
\eta_{\mathrm{m}}(\%)\end{array}$ & $\begin{array}{l}\text { Ultimate load } \\
\qquad P(\mathrm{~N})\end{array}$ & $\begin{array}{l}\text { Actual ultimate } \\
\text { strength } \\
f_{\mathrm{a}}(\mathrm{MPa})\end{array}$ & $\begin{array}{c}\text { Nominal ultimate } \\
\text { strength } \\
f_{\mathrm{n}}(\mathrm{MPa})\end{array}$ & $f_{\mathrm{a}} / f_{0}$ & $f_{\mathrm{n}} / f_{0}$ \\
\hline 1.81 & 561.95 & 1380.19 & 1271.98 & 1.10 & 1.02 \\
\hline 3.48 & 582.42 & 1430.47 & 1318.32 & 1.14 & 1.05 \\
\hline 3.90 & 557.01 & 1368.08 & 1260.82 & 1.09 & 1.01 \\
\hline 4.25 & 556.90 & 1406.59 & 1260.56 & 1.12 & 1.01 \\
\hline 4.45 & 504.55 & 1239.22 & 1142.06 & 0.99 & 0.91 \\
\hline 6.05 & 561.25 & 1417.59 & 1270.42 & 1.13 & 1.01 \\
\hline 7.35 & 527.90 & 1333.36 & 1194.92 & 1.07 & 0.95 \\
\hline 7.90 & 521.50 & 1394.65 & 1180.43 & 1.11 & 0.94 \\
\hline 7.91 & 548.17 & 1424.39 & 1240.80 & 1.14 & 0.99 \\
\hline 9.00 & 539.40 & 1401.61 & 1220.96 & 1.12 & 0.98 \\
\hline 14.16 & 476.89 & 1313.13 & 1079.45 & 1.05 & 0.86 \\
\hline 14.21 & 514.56 & 1416.86 & 1164.72 & 1.13 & 0.93 \\
\hline 15.23 & 512.80 & 1412.02 & 1160.74 & 1.13 & 0.93 \\
\hline 15.85 & 518.13 & 1469.61 & 1172.82 & 1.17 & 0.94 \\
\hline 17.22 & 512.06 & 1452.37 & 1159.06 & 1.16 & 0.93 \\
\hline 23.60 & 461.79 & 1435.47 & 1045.28 & 1.15 & 0.84 \\
\hline 25.06 & 433.34 & 1390.14 & 980.88 & 1.11 & 0.78 \\
\hline 26.94 & 429.89 & 1379.06 & 973.07 & 1.10 & 0.78 \\
\hline 27.29 & 454.31 & 1504.79 & 1028.34 & 1.20 & 0.82 \\
\hline 27.48 & 453.80 & 1503.12 & 1027.20 & 1.20 & 0.82 \\
\hline 54.64 & 267.29 & 1477.07 & 605.01 & 1.18 & 0.48 \\
\hline 57.02 & 245.44 & 1356.34 & 555.56 & 1.08 & 0.44 \\
\hline 57.14 & 278.89 & 1678.11 & 631.27 & 1.34 & 0.50 \\
\hline 57.25 & 211.05 & 1166.31 & 477.72 & 0.93 & 0.38 \\
\hline 57.53 & 222.39 & 1531.41 & 503.39 & 1.22 & 0.40 \\
\hline 62.63 & 202.60 & 1612.27 & 458.60 & 1.29 & 0.37 \\
\hline 75.11 & 122.54 & 1733.64 & 277.38 & 1.39 & 0.22 \\
\hline 78.69 & 94.00 & 1423.08 & 212.77 & 1.14 & 0.17 \\
\hline 87.48 & 57.97 & 1281.46 & 131.22 & 1.02 & 0.10 \\
\hline
\end{tabular}

* The data of $55.60 \%$ corrosion are discarded due to failure in test. 


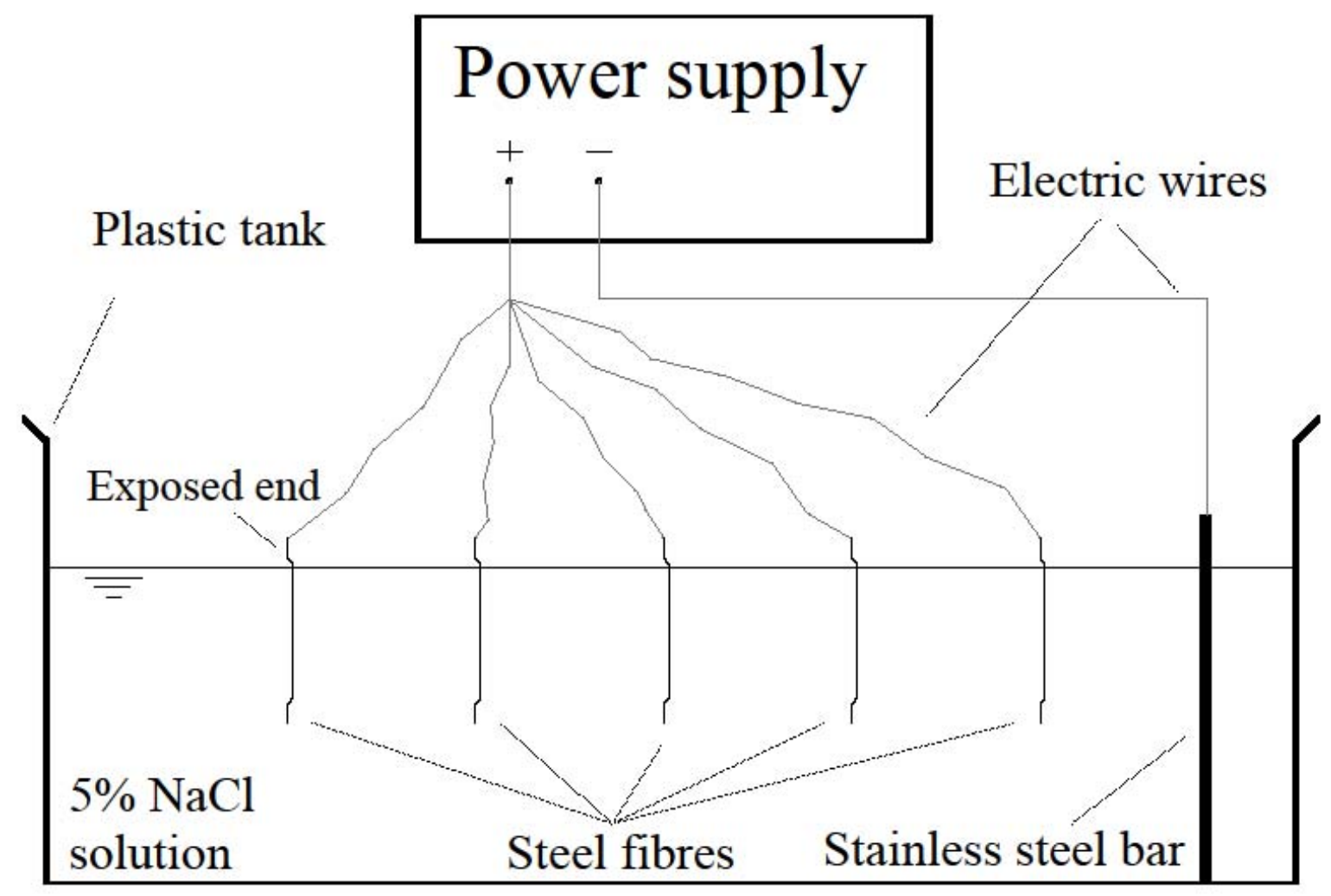

Fig. 1. Schematic representation of the set up for accelerated corrosion using galvanostatic method 


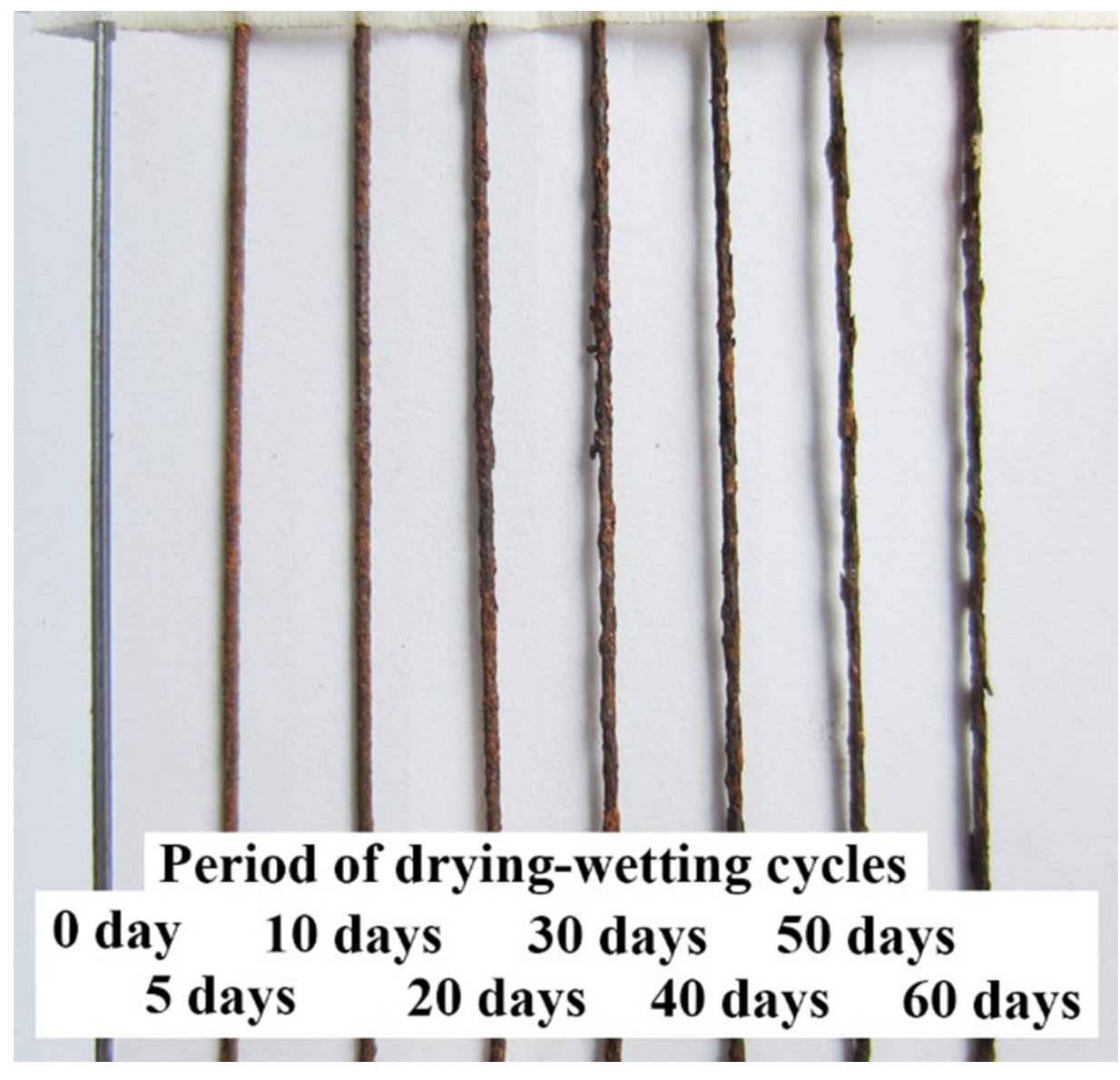

Fig. 2. Steel fibres after exposing to drying-wetting cycles 


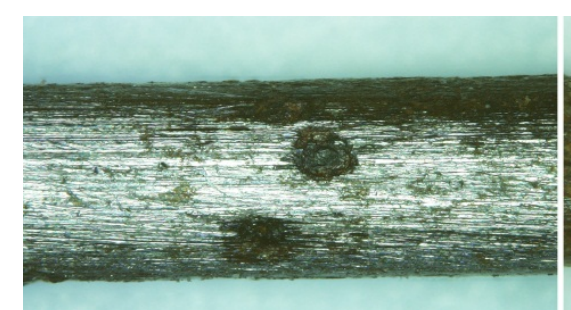

\section{$1.67 \%$}

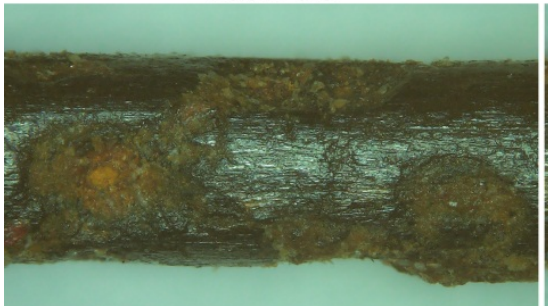

$12.68 \%$

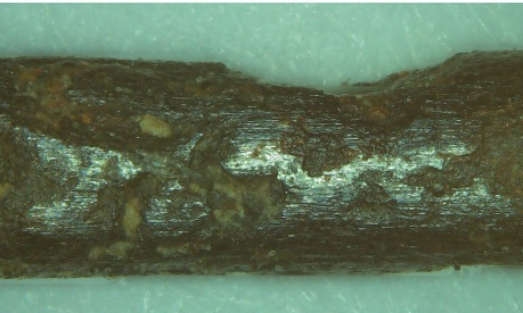

$27.11 \%$

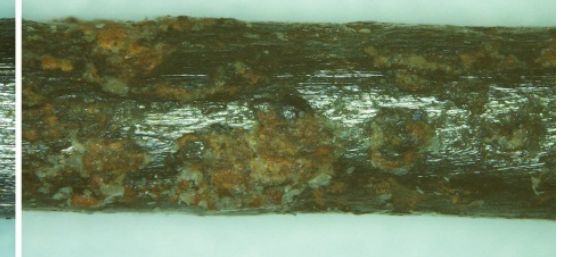

$4.67 \%$

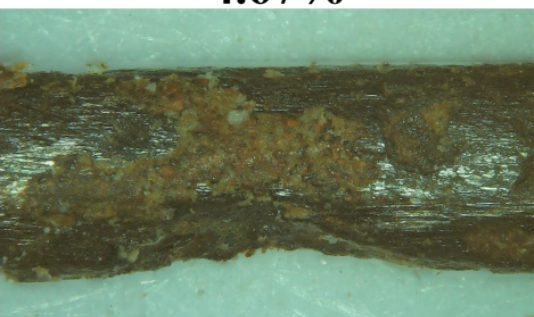

$19.71 \%$

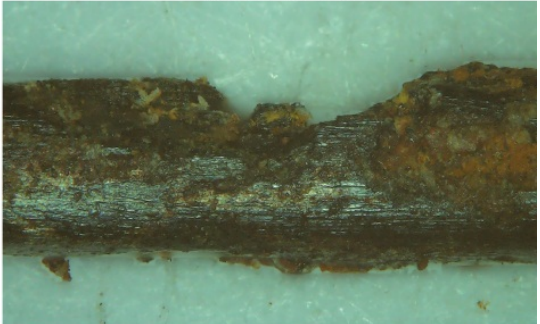

$32.49 \%$

Fig. 3. Pitting of steel fibres with varying degrees of corrosion 


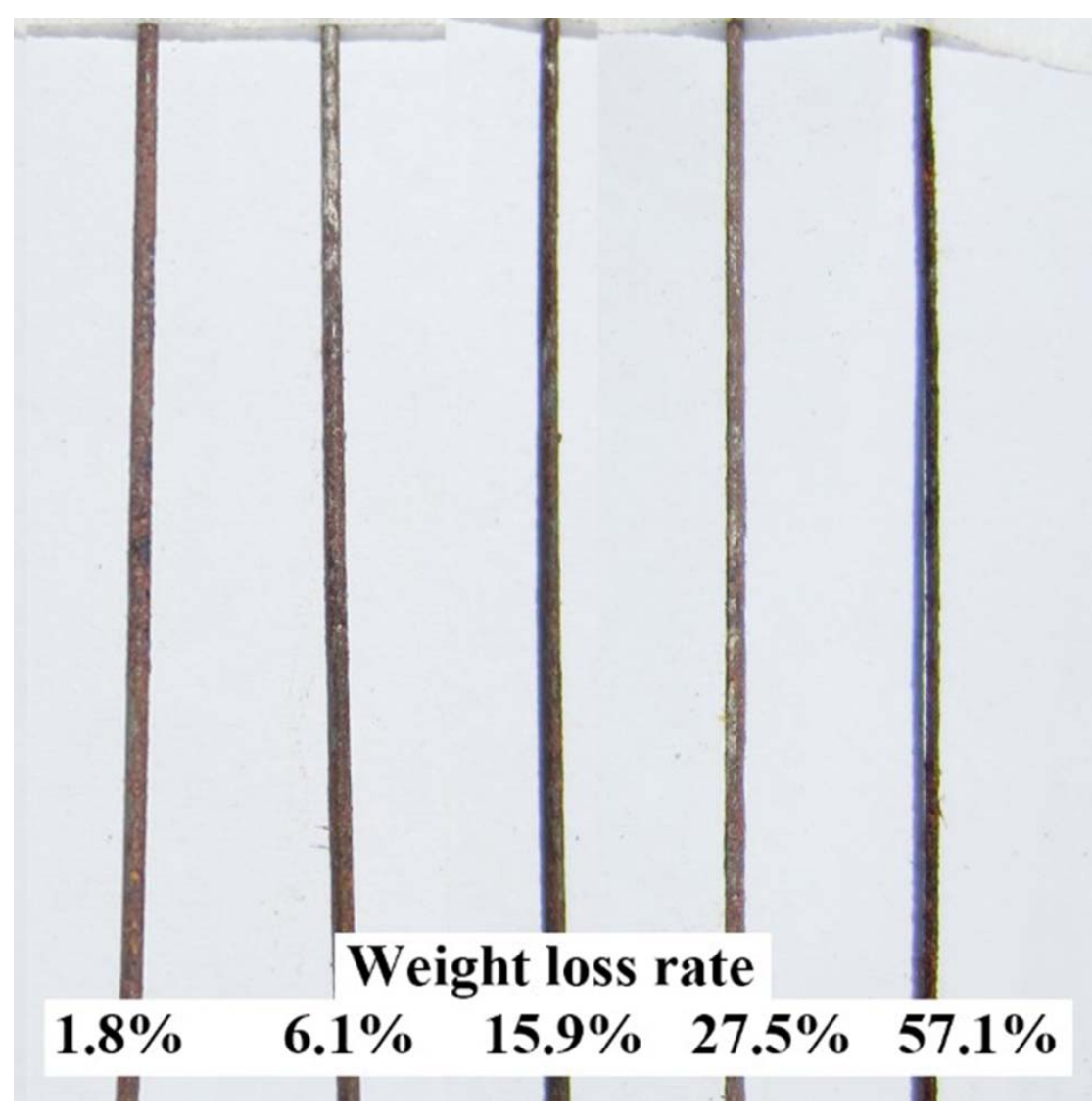

Fig. 4. Steel fibres corroded by galvanostatic method 


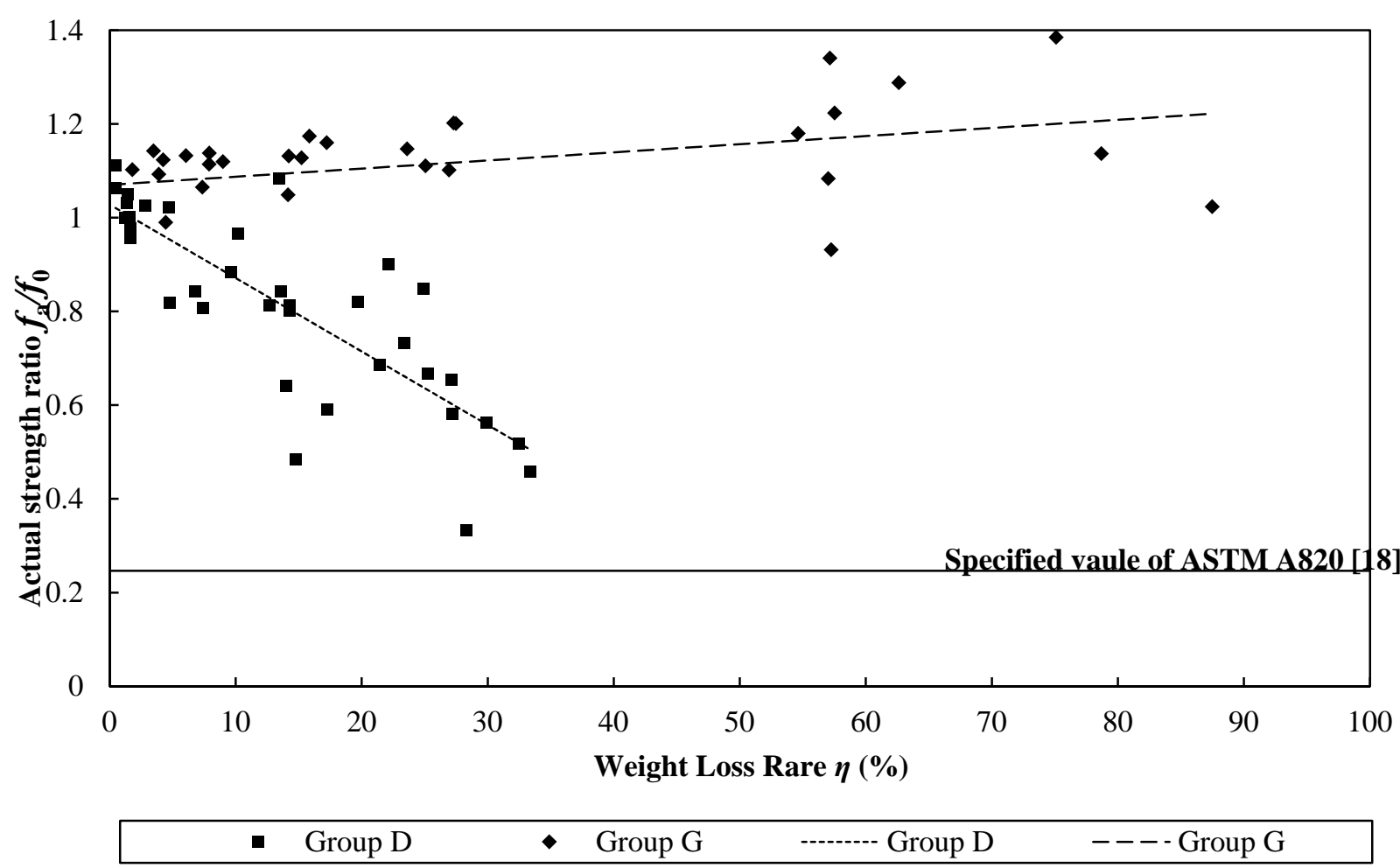

Fig. 5. Actual tensile strength ratio for corroded steel fibres with varying degrees of corrosion 


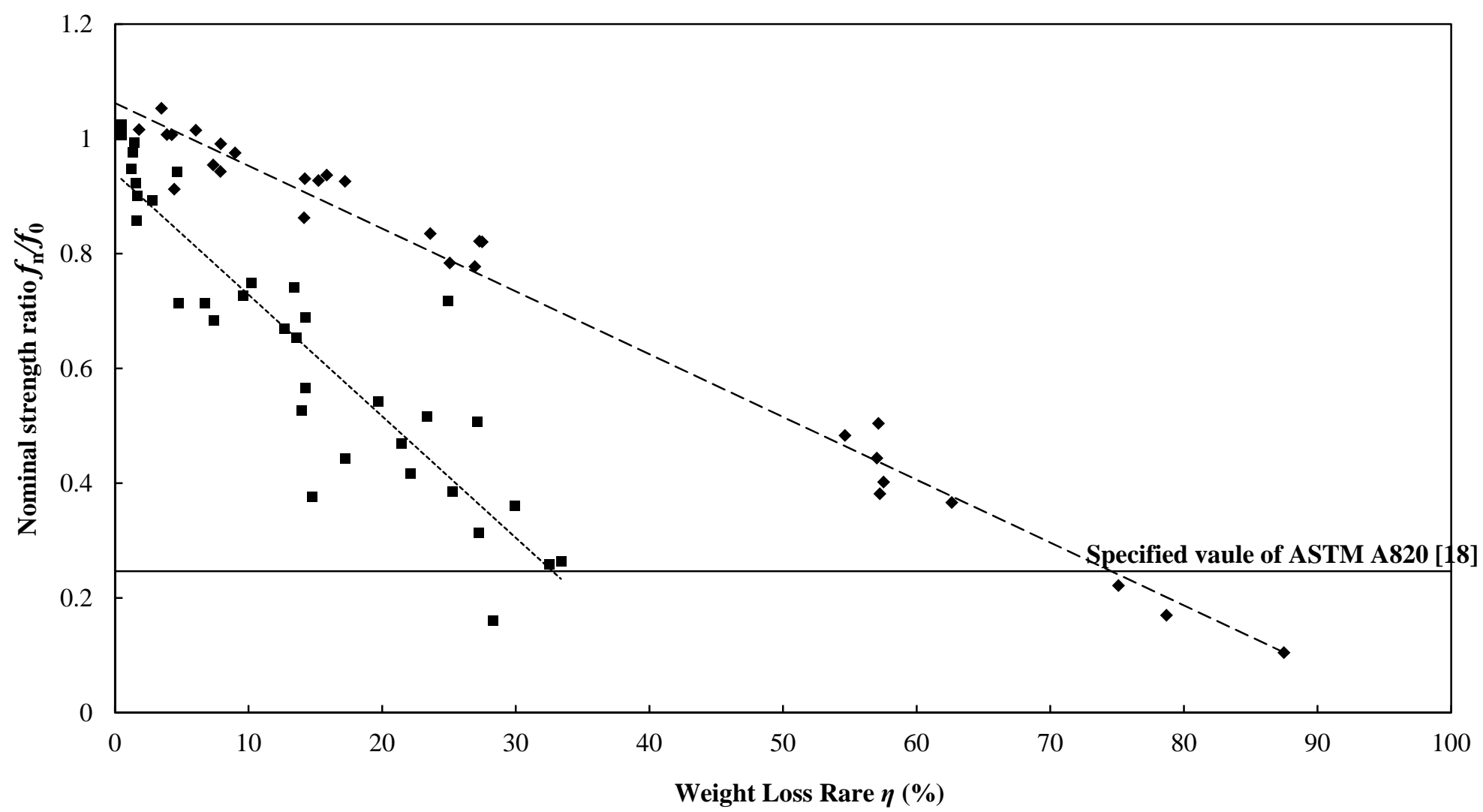

- Group D

- Group G

------- Group D

--- - Group G

Fig. 6. Nominal tensile strength ratio for corroded steel fibres with varying degrees of corrosion 


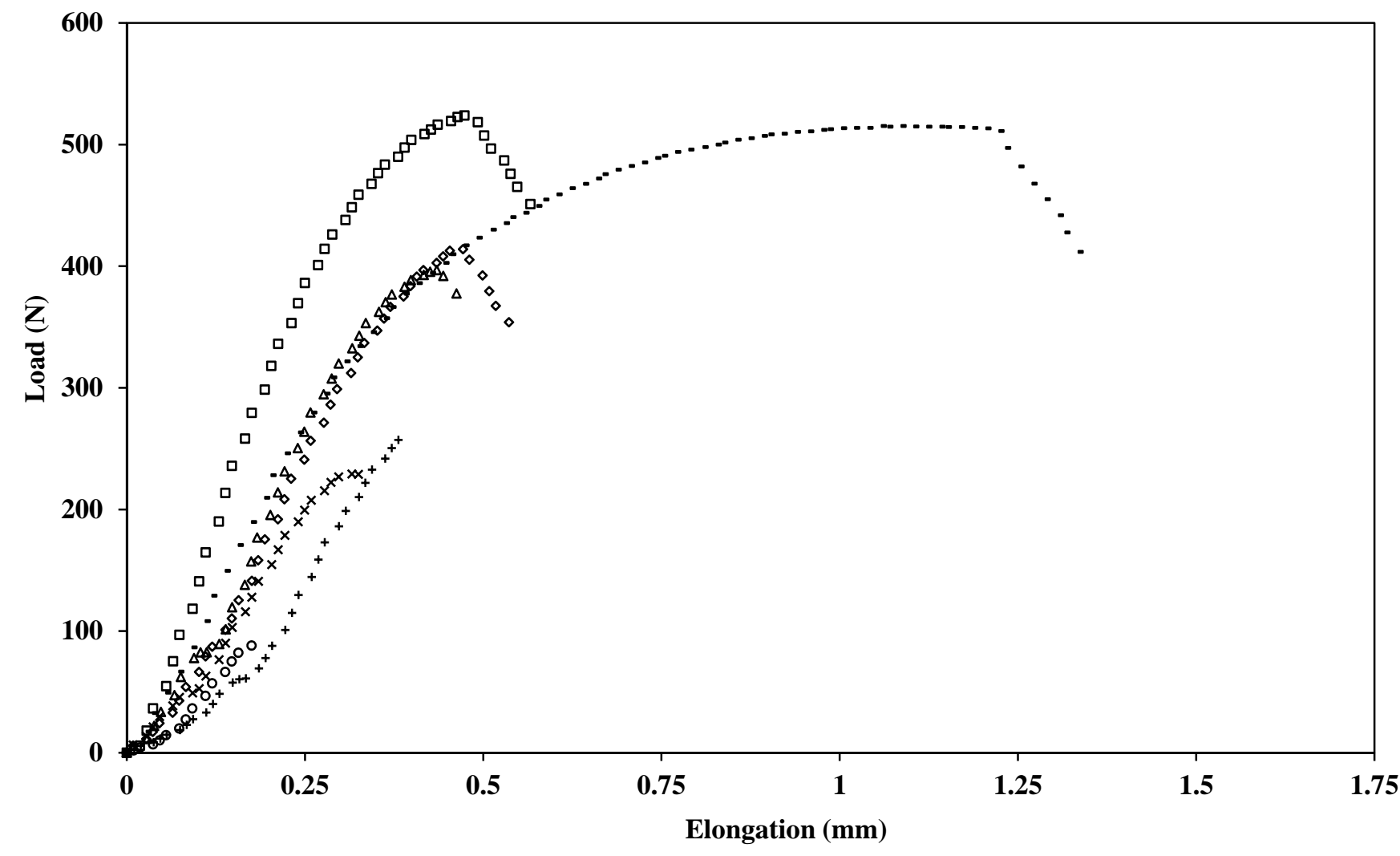

$\begin{array}{lllllll}-0 \% & \circ 1.67 \% & \circ 4.67 \% & \Delta 12.68 \% & +19.71 \% & \times 27.11 \% & \circ 32.49 \%\end{array}$

Fig. 7. Load-elongation curves for steel fibres corroded by drying-wetting cycles 


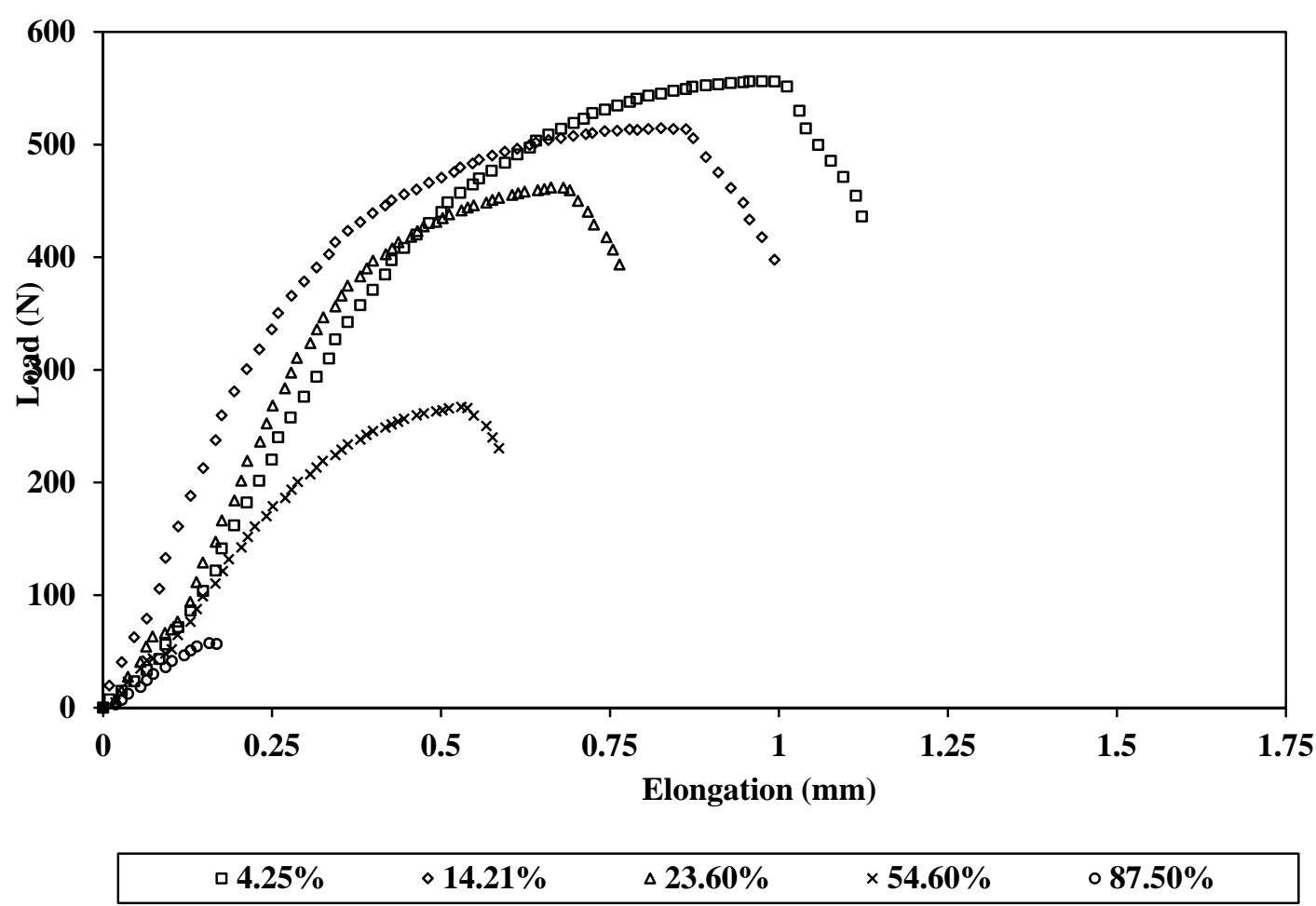

Fig. 8. Load-elongation curves for steel fibres corroded using galvanostatic method 